ORIGINAL ARTICLE

\title{
EAPP: Gatekeeper at the crossroad of apoptosis and p21-mediated cell-cycle arrest
}

\author{
P Andorfer and H Rotheneder \\ Max F. Perutz Laboratories, Department of Medical Biochemistry, Medical University of Vienna, Vienna, Austria
}

\begin{abstract}
We previously identified and characterized E2F-associated phospho-protein (EAPP), a nuclear phosphoprotein that interacts with the activating members of the E2F transcription factor family. EAPP levels are frequently elevated in transformed human cells. To examine the biological relevance of EAPP, we studied its properties in stressed and unstressed cells. Overexpression of EAPP in U2OS cells increased the fraction of G1 cells and lead to heightened resistance against DNA damage- or E2F1-induced apoptosis in a p21-dependent manner. EAPP itself becomes upregulated in confluent cells and after DNA damage and stimulates the expression of p21 independently of p53. It binds to the p21 promoter and seems to be required for the assembly of the transcription initiation complex. RNAi-mediated knockdown of EAPP expression brought about increased sensitivity towards DNA damage and resulted in apoptosis even in the absence of stress. Our results indicate that the level of EAPP is critical for cellular homeostasis. Too much of it results in G1 arrest and resistance to apoptosis, which, paradoxically, might favor cellular transformation. Too little EAPP seems to retard the expression not only of the p21 gene, but also of a number of other genes and ultimately results in apoptosis.
\end{abstract}

Oncogene (2011) 30, 2679-2690; doi:10.1038/onc.2010.639; published online 24 January 2011

Keywords: EAPP; p21; apoptosis; DNA damage; cell-cycle arrest

\section{Introduction}

The cell cycle of all eukaryotes is controlled by cyclindependent kinases (CDKs), the catalytic partners of cyclins (Sherr and Roberts, 2004). A variety of checkpoint mechanisms have evolved that monitor cell-cycle progression and respond to perturbations like replication errors or DNA damage by modifying the activity of CDKs (Hartwell and Weinert, 1989; Pietenpol and Stewart, 2002). Cyclin-dependent kinase

Correspondence: Dr H Rotheneder, Max F. Perutz Laboratories, Department of Medical Biochemistry, Medical University of Vienna, Dr Bohr-Gasse 9/2, A-1030 Vienna, Austria.

E-mail: Johann.Rotheneder@meduniwien.ac.at

Received 16 August 2010; revised 1 December 2010; accepted 20 December 2010; published online 24 January 2011 inhibitors interact with CDKs and inhibit their activity (Chen et al., 1996). The tumor suppressor p53 is a component of several checkpoints (Giono and Manfredi, 2006) and controls the expression of various growthinhibitory or apoptotic genes (Rozan and El-Deiry, 2007). Among these is the $C D K N 1 A$ gene that codes for $\mathrm{p} 21$ (or $\mathrm{p} 21^{\mathrm{WAF} 1 / \mathrm{Cip} 1}$ ), which induces growth arrest by binding and inhibiting CDK complexes (el-Deiry et al., 1993; Chen et al., 1995; Goubin and Ducommun, 1995) and by sequestering away proliferating cell nuclear antigen from DNA polymerase $\delta$ (Flores-Rozas et al., 1994; Waga et al., 1994). Thereby, but also by its ability to promote cellular senescence and differentiation, p21 prevents the development of tumors (for reviews see (Abbas and Dutta, 2009; Cazzalini et al., 2010). In addition, p21 influences gene expression via certain promoter elements (Zhu et al., 2002) and by its interaction with transcription factors (Delavaine and La Thangue, 1999; Kitaura et al., 2000). Paradoxically, p21 also prevents apoptosis (Roninson, 2002) on the one hand because the initiation of apoptosis often requires an active cell cycle, on the other hand by interference with apoptotic signaling (Asada et al., 1999) and caspase activation (Suzuki et al., 1999; Baptiste-Okoh et al., 2008) Some of these antiapoptotic activities depend on the cytoplasmic localization of p21 (Blagosklonny, 2002).

We have previously identified and characterized an E2F-binding protein, which we termed E2F-associated phospho-protein (EAPP) (Novy et al., 2005) and which we found overexpressed in many tumor cell lines. EAPP interacts with E2F1-3, comprising the activator group of E2F proteins, and modulates E2F-dependent transcription. Its expression is regulated by the transcription factors Sp1, Sp3 and Egr-1 binding to the TATA-less promoter of the EAPP gene (Schwarzmayr et al., 2008). Very recently it has been shown that EAPP negatively regulates the expression of monoaminoxidase $\mathrm{B}$ via $\mathrm{Sp} 1$ binding sites (Chen et al., 2010).

We show in this study that EAPP levels increase upon DNA damage and higher EAPP levels seem to protect cells from apoptosis. This protection can also be achieved by ectopic expression of EAPP and correlates with an increased number of cells in G1 phase and an upregulation of $\mathrm{p} 21$. RNAi-mediated knockdown of $\mathrm{p} 21$ abrogates this effect of EAPP. Knockdown of EAPP on the other hand results in apoptosis. We analyzed the expression of p 21 by western, reverse transcription-PCR (RT-PCR) and reporter gene assays and could show 
that the knockdown of EAPP reduces p21 mRNA and protein, whereas overexpression of EAPP results in elevated p21 levels. Chromatin immunoprecipitation (ChIP) experiments demonstrated that EAPP binds to the p21 promoter in the vicinity of the TATA box and might be involved in transcription initiation.

\section{Results}

Overexpression of EAPP alters cell-cycle progression We have shown earlier that EAPP can influence the cell cycle and many transformed cell lines exhibit elevated levels of EAPP (Novy et al., 2005). To examine whether EAPP is involved in the response to stress, we compared the effects of certain drugs known to inhibit cell-cycle progression in cells with different EAPP levels. We transfected U2OS cells with either an expression vector for EAPP or an empty vector and treated these cells with nocodazole and colchicine that arrest cells in mitosis by interfering with the assembly of the mitotic spindle, or with etoposide and methyl-methanesulfonate, which cause DNA damage and cell-cycle arrest, preferentially in $\mathrm{S}$ or G2 phase. Subsequently the cells were analyzed by flow cytometry. In all four cases the ectopic expression of EAPP brought about a prominent G1 peak not present in mock-transfected cells (Figure 1a). As it is very improbable that EAPP can overcome the effects of four different drugs, the most likely explanation seemed to be an EAPP-induced slowing-down of the cell cycle resulting in an accumulation of cells in G1. Gating of U2OS cells expressing a green fluorescent protein (GFP)-tagged version of EAPP revealed that the cells that expressed GFP-EAPP had a higher G1 fraction than those that did not (Figure 1b).

The EAPP-induced $G 1$ arrest is mediated by $p 21$

Cells approaching confluency usually grow slower and this is at least partially caused by elevated p21 (Perucca et al., 2009). As overexpression of EAPP resulted in slower growth, we checked whether EAPP also goes up with increasing cell density. Figure 2 a shows that this is indeed the case, suggesting a possible connection between the two proteins. To examine this we expressed either GFP or GFP-EAPP with or without a p21-specific small interfering RNA in U2OS cells (Figure 2b). The GFP-positive cells were then analyzed by flow cytometry to determine and compare the fraction of cells in G1-, S- or G2-phase (Figures 2c and d). The comparison of GFP-positive and GFP-negative cells on the one hand and of GFP- and GFP-EAPPexpressing cells on the other hand demonstrated again the cell cycle slowing property of EAPP. The knockdown of p21 abrogated this growth-retarding effect, suggesting that it is exclusively or at least primarily mediated by $\mathrm{p} 21$.

\section{EAPP regulates p 21 expression via $S p 1$ sites and binds to the p21 promoter}

Western analysis showed that increasing the level of EAPP results in higher $\mathrm{p} 21$, whereas a knockdown of EAPP lowers p21 (Figure 3a). To find out whether EAPP influences the expression or the stability of $\mathrm{p} 21$, we first performed RT-PCR and compared the p21 mRNA levels in cells with lowered, normal and elevated EAPP. Figure $3 b$ shows that knockingdown EAPP resulted in a concomitant reduction of p21 mRNA, whereas overexpression of EAPP caused a modest rise of p21 mRNA. To determine whether EAPP influences p21 mRNA levels by affecting promoter activity, we carried out reporter assays. It turned out that the knockdown of EAPP reduced promoter activity, whereas its ectopic expression stimulated the promoter (Figure 3c). Conversely, the cyclin A promoter was not inhibited by the knockdown of EAPP but even slightly stimulated (Supplementary Figure 2). A major determinant for the transcription rate of a protein-coding gene is its occupancy by RNA polymerase II (Pol II). To examine whether EAPP can influence the activity
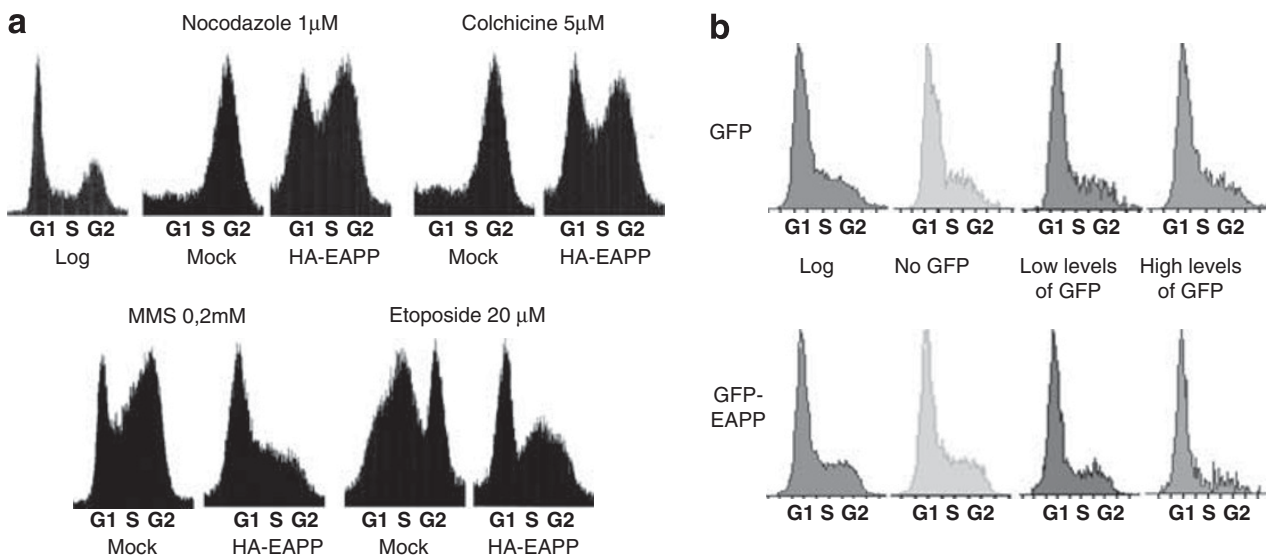

Figure 1 EAPP overexpression increases the G1 fraction of U2OS cells. (a) U2OS cells were transfected with an expression vector for HA-EAPP or a control vector and treated with different drugs for $16 \mathrm{~h}$. Nocodazole and colchicine arrest cells during mitosis, etoposide and methyl-methanesulfonate cause DNA damage, hence stall cells in S-phase. Harvested cells were analyzed for cell-cycle distribution. (b) To investigate untreated cells either a GFP-EAPP or a GFP control vector were transfected into U2OS cells, gated for their GFP levels and separately analyzed. 
a

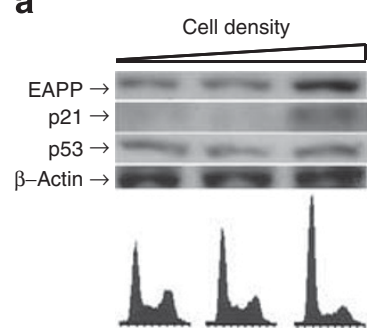

d

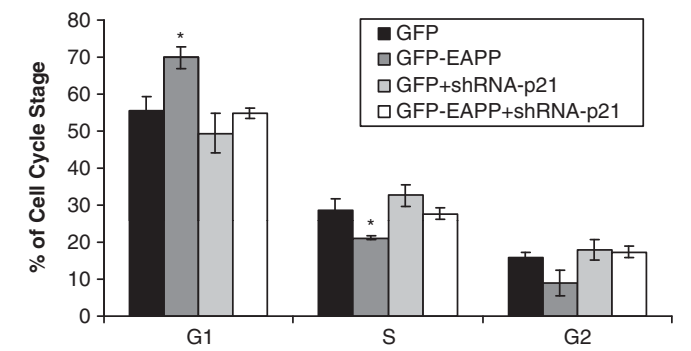

b

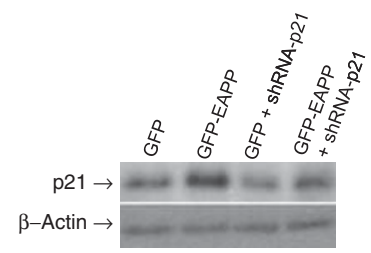

C

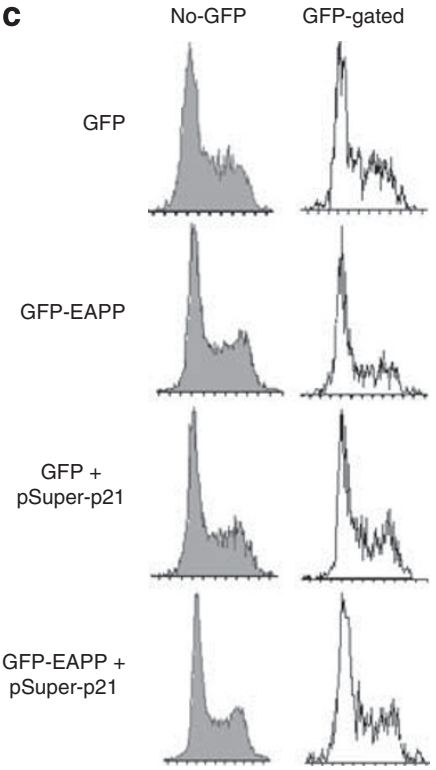

Figure 2 p21 has a major role in the EAPP-triggered G1 cell-cycle arrest. Its knockdown abrogates the growth-inhibiting effect of EAPP. (a) Rising cell density results in higher EAPP and p21 levels as shown on a western blot (upper panel) and increases the fraction of G1 cells as shown by FACS analysis (lower panel). (b) U2OS cells were transfected with expression vectors for GFP or GFP-EAPP with or without an expression vector for small hairpin RNA targeting p21 mRNA and analyzed by western blotting and immunostaining with an anti-p21 antibody. (c) The same cells were gated for GFP expression and separately analyzed by flow cytometry. (d) The cell-cycle distribution of GFP-positive cells of three independent experiments were quantified with FlowJo (Tree Star Inc, Ashland, OR, USA) and averaged. All data are presented as the mean \pm s.d. from at least three independent experiments. ${ }^{*} P<0.05$.

of Pol II on the 221 gene, we performed ChIP with an anti-Pol II antibody. These experiments demonstrated that the presence of Pol II on the exon 1 of the $p 21$ gene is severely reduced upon knockdown of EAPP (Figure 3d). To determine the sequence requirements for the observed effects, we carried out luciferase assays with the full-length p21 promoter and several truncations thereof (Figure 3e) and compared their activity under normal and EAPP knockdown conditions. The proximal promoter comprising four of the six $\mathrm{Sp} 1$ (nucleotides -101 to +16 relative to the transcription start site) is sufficient to confer regulation by EAPP (Figure 3f). Mutation of either one of the two distal of these sites (Sp1 binding sites 3 and 4) abolished the influence of EAPP (Figure 3g).

To figure out whether EAPP is associated with the p21 promoter, we conducted ChIP assays and amplified precipitated DNA from five different regions of the $p 21$ gene (Figure 4a). Appreciable precipitation with an antiEAPP antibody could only be achieved with the region comprising the TATA box (Figure $4 \mathrm{~b}$ ).

\section{EAPP seems to influence the assembly of the preinitiation complex}

Histone modification is one of the key mechanisms in transcriptional regulation. The protruding $N$-terminal domains of histones are subject to methylation, acetylation and phosphorylation (Li et al., 2007b). We performed ChIP assays with modification-specific anti-histone antibodies to investigate whether EAPP alters the histone modification status of the promoter and thereby influences $p 21$ transcription. Neither the general acetylation of $\mathrm{H} 3$ and
$\mathrm{H} 4$, nor the specific $\mathrm{K} 9$ acetylation on $\mathrm{H} 3$, nor the phosphorylation of $\mathrm{S} 10$ on $\mathrm{H} 3$ showed any alteration upon EAPP knockdown (Supplementary Figure 3). The binding of p53 to its cognate binding sites further upstream on the p21 promoter also remained unchanged (Figure 4c). Interestingly, a fraction of p53 can also be found at the TATA region. It might represent Sp1-associated p53 (Lagger et al., 2003) and/or might be brought to the TATA box by looping of the DNA (Li et al., 2007a). This fraction of p53 was reduced upon EAPP depletion (Figure 4c).

Binding of TBP at the TATA box and bending of the DNA is considered the first step in the assembly of the preinitiation complex on TATA box containing promoters. This is followed by the recruitment of TAFs (TBP associated factors) to constitute TFIID, the binding of the other components of the basal transcription machinery and finally the association with RNA pol II (reviewed in (Kornberg, 2007; Sikorski and Buratowski, 2009)). To examine whether reducing EAPP interferes with the build up of the transcription initiation complex, we again carried out ChIP assays in EAPP knockdown and control cells. Reduction of EAPP did not influence the binding of TBP but the presence of TAF 1 and TAF 4, Pol II and cdk 9 was clearly reduced in these cells. In contrast, the binding of transcription factors was either not affected (E2F1) or even increased (Spl) by lower EAPP levels (Figures 4c, $d$ and e).

\section{EAPP is involved in the DNA damage-induced upregulation of $p 21$}

DNA damage results in the induction of p53, which in turn stimulates the expression of $\mathrm{p} 21$. We used 

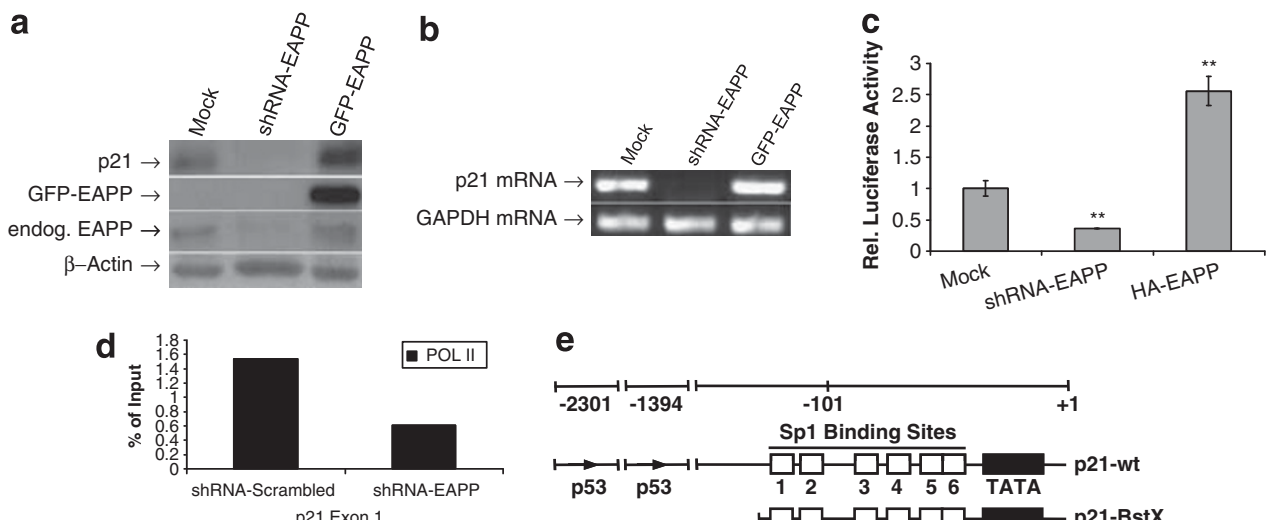

e
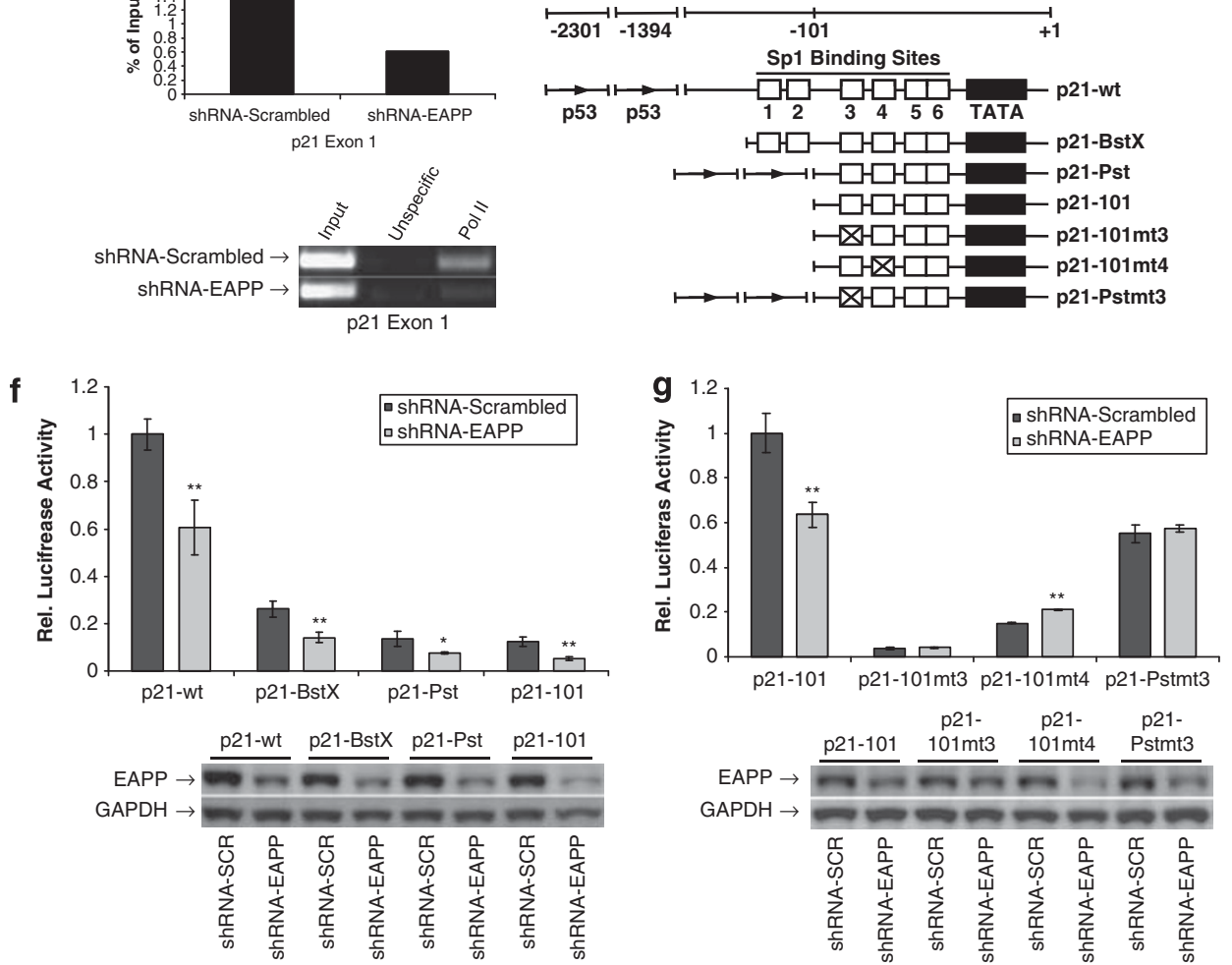

Figure 3 EAPP regulates p21 at the level of transcription via Sp1 binding sites. (a) Western blot showing a p21 decrease after knock down of EAPP and an increase upon EAPP overexpression. $\beta$-Actin served as a loading control (b) RT-PCR of p21 mRNA after EAPP knockdown and overexpression. (c) Reporter assay with the full-length p21 promoter. Knockdown of EAPP decreases the Luciferase activity, whereas overexpression results in an increase. (d) ChIP showing exon 1 associated RNA pol II in EAPP knockdown and control cells. The lower panel depicts the actual data, the upper panel the quantification. pSuper-Scrambled is the RNAi control vector for the expression of an unspecific small hairpin RNA. (e) Schematic illustration of the used p21 luciferase constructs. (f, g) Luciferase assays with p21 promoter constructs under normal and EAPP knockdown conditions. A luciferase activity of 1 was assigned to the p21-wt promoter in $\mathbf{f}$ and to the p21-101 promoter in $\mathbf{g}$. The lower panels are western blots showing the respective EAPP levels with GAPDH as a loading control. All data are presented as the mean \pm s.d. from at least three independent experiments. ${ }^{*} P<0.05 ;{ }^{* *} P<0.01$.

p53-positive U2OS cells to find out whether EAPP is not only required for basal expression, but also takes part in the stress-induced activation of p21. DNA damage was induced with etoposide and p21 mRNA expression was examined with lowered, normal and elevated EAPP levels (Figure 5). Overexpression of EAPP not only increased p21 mRNA in control cells, but also in etoposide-treated cells with already elevated p21 mRNA (Figure 5a). In p53 negative T98G cells, the overall level of p21 mRNA was much lower but still stimulated by EAPP, indicating that this effect is p53-independent (Figure 5b). To follow the induction of EAPP by etoposide more closely, time-course experiments were performed. Figure $5 \mathrm{c}$ shows the level of p21 mRNA and EAPP between 0 and $9 \mathrm{~h}$ after etoposide addition. Their parallel increase in both, normal and
EAPP knockdown cells indicates that besides p53, DNA damage-induced EAPP might also contribute to the upregulation of the p21 promoter. Protein levels of p21 also increased and decreased with EAPP in normal and etoposide-treated cells. DNA damage-induced p53 was not affected by changes in EAPP levels. Inhibition of histone deacetylase (HDAC) activity by TSA also resulted in elevated p21 and EAPP levels. The knockdown of EAPP lowered p21 also in the presence of TSA, confirming that this effect is not acetylation dependent (Supplementary Figure 4).

\section{EAPP has antiapoptotic properties that depend on p21} In EAPP overexpressing cells, the fraction of apoptotic cells following etoposide addition was clearly reduced 
a
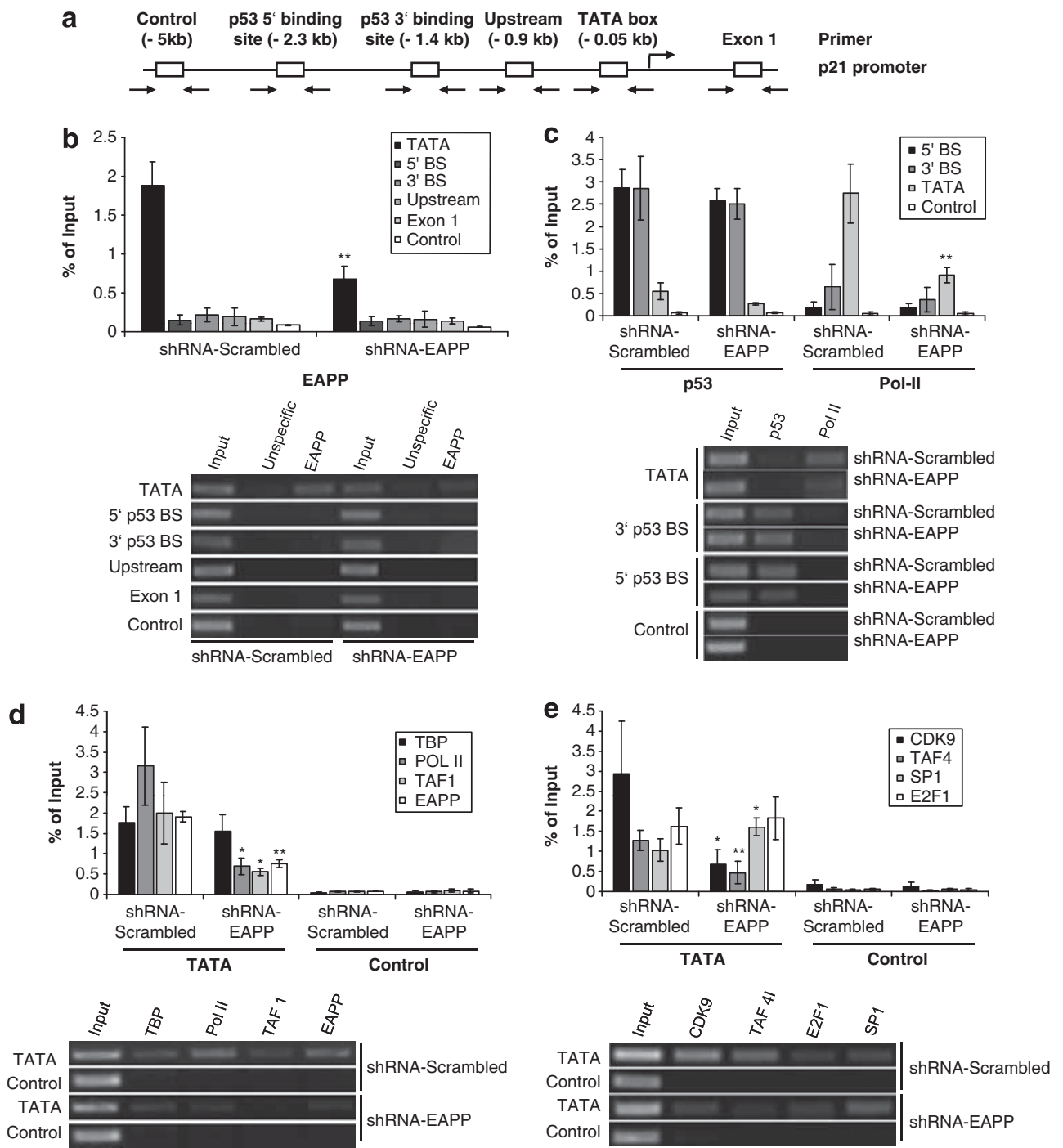

Figure 4 EAPP binds around the TATA box of the p21 promoter and influences the binding or assembly of the basal transcription machinery and Sp1. (a) Schematic drawing of the p21 promoter region depicting the regions that were amplified after ChIP to characterize EAPP binding. (b) ChIP experiments in U2OS cells showed that EAPP could only be found in the region amplified by the TATA box primer pair. The lower panel shows a representative experiment, the upper panel the quantification. (c) ChIP assays with p53- and Pol II-specific antibodies probing the p53-binding sites and the TATA box region. (d, e) ChIP assays with TAF1-, TAF4-, Pol II-, CDK9-, E2F1- and Sp1-specific antibodies of the TATA and control regions. All data are presented as the mean \pm s.d. from at least three independent experiments. ${ }^{*} P<0.05 ; * * P<0.01$.

(Figure 6a). Quantification showed a significant smaller fraction of apoptotic cells in EAPP overexpressing cells even after prolonged exposure to etoposide (Figure 6b). The same result was obtained by analyzing the apoptotic fraction in the forward/side scatter plot in flowcytometric analysis. Apoptotic cells have lower forward scatter and slightly higher side-scatter values and appear as a distinguishable population (not shown). Apoptosis can also be induced by overexpression of E2F1 (Qin et al., 1994; Shan and Lee, 1994; Wu and Levine, 1994) in p53-dependent and -independent manners (Phillips and Vousden, 2001), which again was prevented by the simultaneous expression of EAPP (Figures 6c and d). If apoptosis can be inhibited by EAPP overexpression, conversely its knockdown should facilitate apoptosis. To test this hypothesis, EAPP levels in U2OS and T98G cells were lowered by RNAi. To make sure that the observed cell death results from apoptosis, we stained the cells with YoPro-1 (Idziorek et al., 1995), which allowed the selection of apoptotic and dead cells and with propidium iodide (PI) that allowed the discrimination between early apoptotic and late apoptotic plus dead cells. In addition, we performed western analysis and looked for cleaved caspase 3, a hallmark of apoptosis. The number of cells with a subG1 DNA content and the amount of cleaved caspase 3 increased dramatically in both, p53-positive U2OS (Figure 7a) and p53-negative T98G cells (Figure 7b) with lowered EAPP, indicating that this effect is p53 independent. 
a
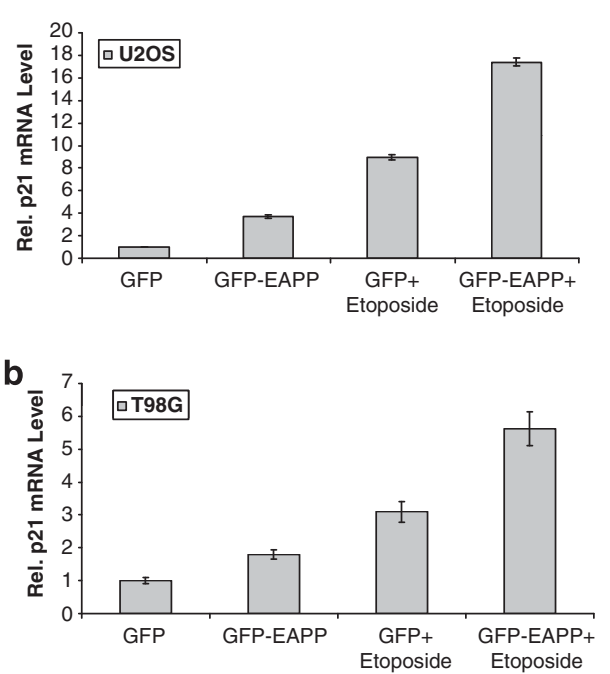

C

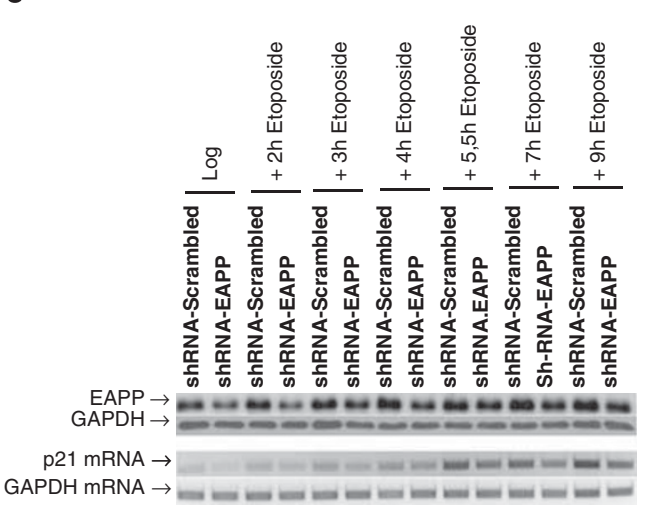

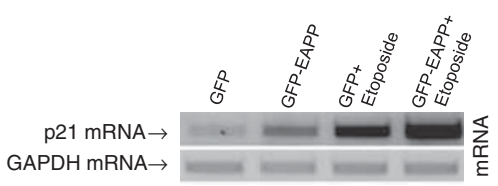
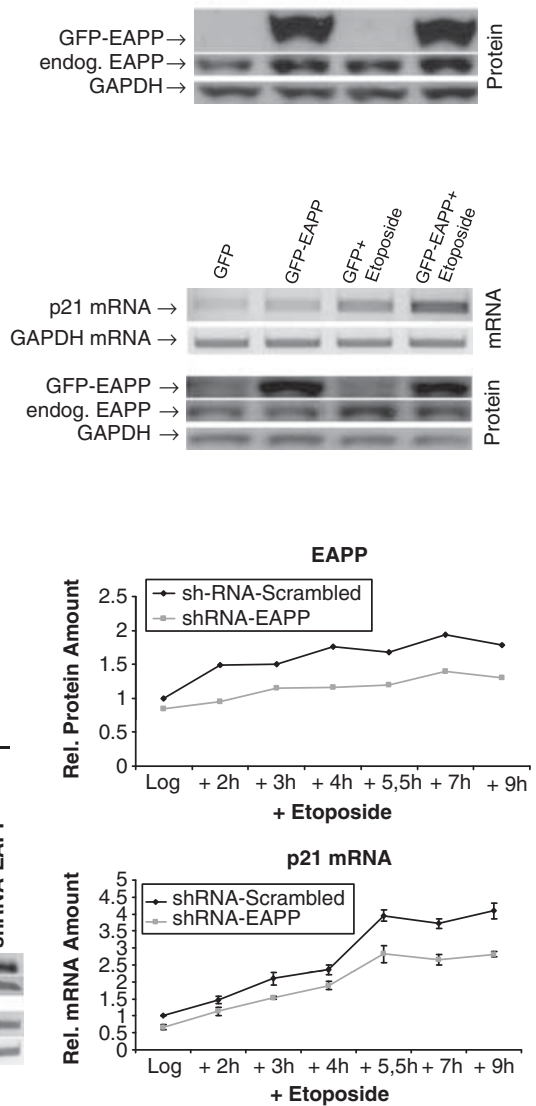

Figure 5 The increase of EAPP upon etoposide treatment might be necessary for the full induction of p21 expression. (a) U2OS cells were transfected with either a GFP- or a GFP-EAPP expression vector in duplicate and one pair was treated with etoposide and analyzed. The right panel shows the mRNA levels of p21 and GAPDH and the protein levels of GFP-EAPP, endogenous EAPP and GAPDH as determined by RT-PCR and western analysis, respectively. The left panel shows the quantification of p21 mRNA levels. (b) The same experiment as shown in b but carried out in T98G cells. (c) U2OS cells were transfected with an EAPP knockdown vector or the corresponding control vector, treated with etoposide and harvested at the indicated time points. EAPP levels were determined by western analysis and p21 mRNA levels by RT-PCR. For better comparison, relative amounts were quantified with ImageQuant with GAPDH and GAPDH mRNA serving as a reference. For the p21 mRNA PCRs were done in triplicate and averaged. The right panels graphically show the increase of EAPP and p21 mRNA with the duration of etoposide treatment. All data are presented as the mean \pm s.d. from at least three independent experiments.

To further investigate the requirement for EAPP, we examined U2OS cells and U2OS cells with moderately lowered EAPP levels under normal and DNA damage conditions. Equal numbers of these cells were seeded either in normal growth medium or in growth medium with low concentrations of etoposide and counted for 4 days. Whereas the number of cells in plain growth medium steadily increased with little difference between normal and EAPP knockdown cells, the number of etoposide-treated cells decreased after an initial rise. This decrease was much more pronounced in the EAPP knockdown cells again emphasizing the protective role of EAPP (Figure 8a). This goes along with a reduced induction of $\mathrm{p} 21$ (Figure $8 \mathrm{~b}$ ) and a much higher degree of apoptosis in EAPP knockdown cells. Staining with YoPro-1 and PI and subsequent flow-cytometric analysis allowed the quantification of this difference (Figures 8c and d).
To examine whether the antiapoptotic activity of EAPP is also mediated by $\mathrm{p} 21$, we determined the fraction of apoptotic cells at 24,48 and $72 \mathrm{~h}$ after the induction of DNA double-strand breaks in control cells, cells with elevated EAPP, cells with lowered p21 and cells with both, elevated EAPP and lowered p21. It turned out that the antiapoptotic activity of EAPP is greatly diminished by the knockdown of p21 (Figure 9). This indicates that this activity of EAPP is indeed mainly mediated by p21 but other factors might also be involved.

\section{Discussion}

Following DNA damage, a cell of a multicellular organism can repair the damage, withdraw from the cell cycle and enter senescence, or eliminate itself by 
a

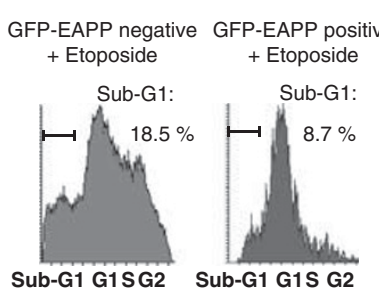

b

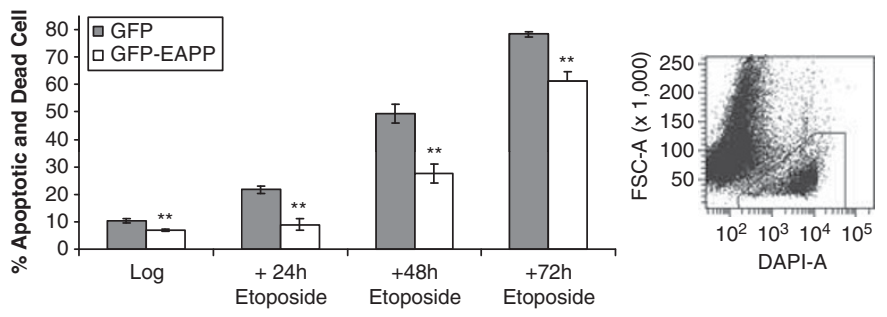

C

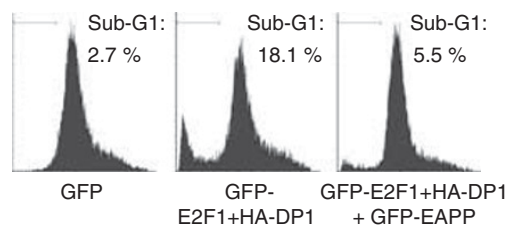

d

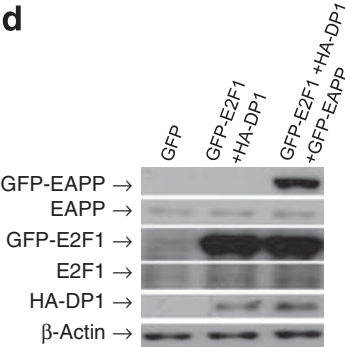

Figure 6 EAPP has antiapoptotic properties. (a) U2OS cells were transfected with a GFP-EAPP expression vector, treated with etoposide for $16 \mathrm{~h}$ and gated for GFP-EAPP expression. There is a massive decrease in S/G2 and sub-G1 at the expense of an increase in G1. (b) Long-term treatment with etoposide of U2OS cells expressing either GFP or GFP-EAPP. GFP-positive cells were gated and apoptosis was measured through an increase in Hoechst 33258 intensity, which brightly stains the condensed chromatin of apoptotic cells (example is shown). All data are presented as the mean \pm s.d. from at least three independent experiments. $* * P<0.01$. (c) U2OS cells were transfected either with a GFP expression vector as a control, with expression vectors for GFP-E2F1 and HA-DP1, or with expression vectors for GFP-E2F1, HA-DP1 and GFP-EAPP. For the flow-cytometric analysis GFP-positive cells were gated and the percentage of sub-G1 cells was determined. (d) The levels of expressed proteins were examined in a western blot.

a

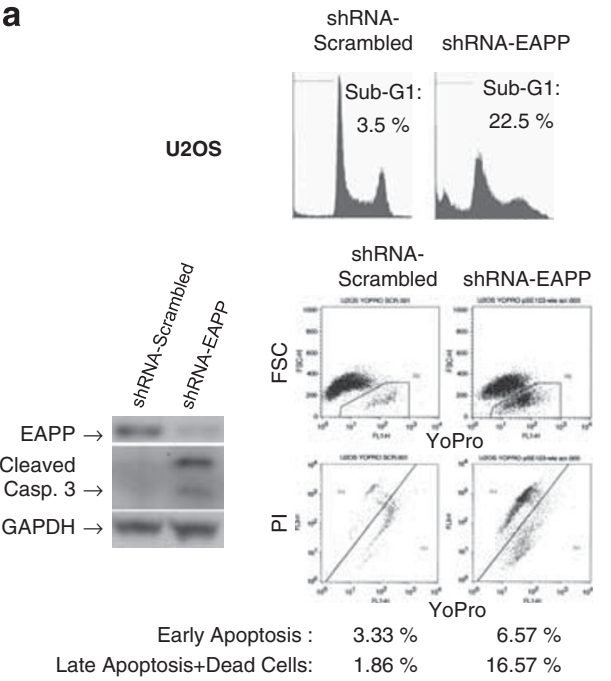

b

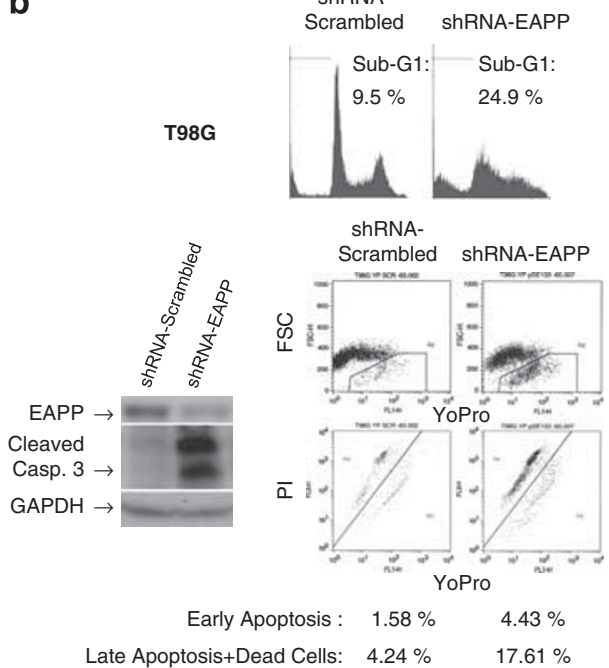

Figure 7 Knockdown of EAPP leads to the induction of apoptosis. (a) U2OS cells were transfected with an EAPP knockdown and a corresponding control vector and analyzed for apoptosis. We examined the sub-G1 fraction, cleaved caspase 3 protein levels by a western blot, and YoPro/PI staining with a Vybrant Apoptosis Assay Kit. The YoPro-positive fraction was gated and separated into PI-negative and -positive cells to distinguish between early apoptosis and late apoptosis plus dead cells, respectively, (FSC $=$ forward scatter). (b) The same was done with p53-negative T98G cells again resulting in an increase of apoptosis.

apoptosis to avoid the proliferation of aberrant descendants, possibly resulting in cancer. Among the main players in this process are the tumor suppressor p53 and its transcriptional target $\mathrm{p} 21$. Treatment of cancer cells with certain drugs often induces p21 followed by cellcycle arrest and/or cellular senescence and this can protect cells from drug-induced apoptosis (Kawasaki et al., 1996; Waldman et al., 1996; Gartel and Tyner,
2002). p21 seems to accomplish this either by inhibiting CDK activity (Chen et al., 1996) or by modulating the activity of transcription factors or apoptosis regulators (Janicke et al., 2007).

EAPP is an evolutionary conserved phosphoprotein with a predominant nuclear localization that is frequently upregulated in transformed cells. We have previously identified it as an E2F-binding protein that 

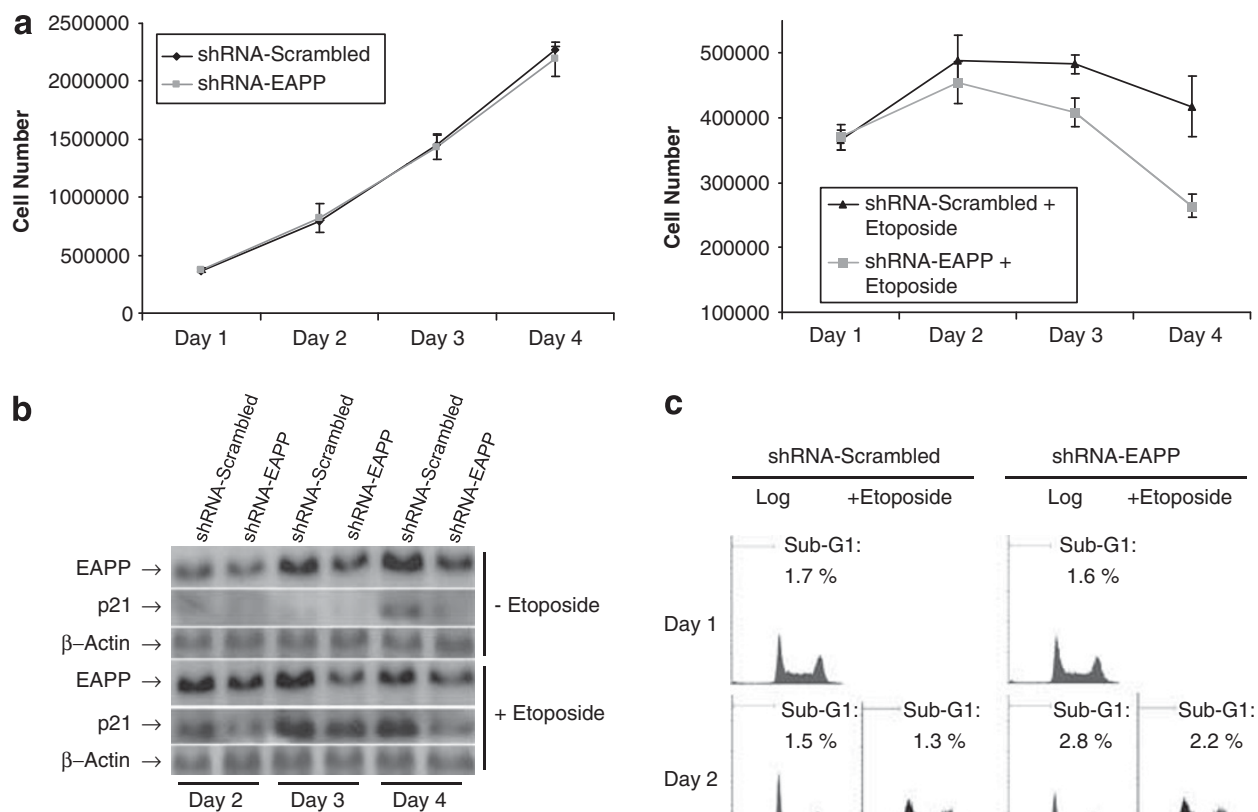

C

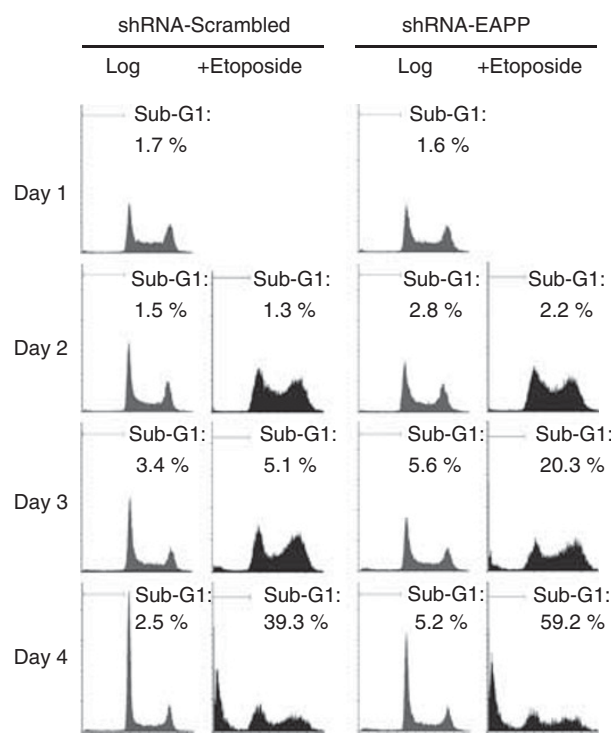

Figure 8 A moderate EAPP knockdown has slight effects on logarithmic U2OS cells but greatly reduces their viability upon etoposide treatment. (a, b) Cells were transfected to accomplish a knockdown of EAPP of about $50 \%$ and treated with or without $5 \mu \mathrm{m}$ etoposide for 3 days. Cells were counted with a Casy Counter every day and corresponding protein levels were checked on a western blot. The growth curve shows the average of three independent experiments. (c) The cell-cycle distribution of these cells was examined and the fraction of sub-G1 cells determined. (d) YoPro/PI staining and gating was carried out as shown in Figure 7. All data are presented as the mean \pm s.d. from at least three independent experiments. ${ }^{*} P<0.05 ; * * P<0.01$.

modulates the activity of E2F-dependent promoters (Novy et al., 2005).

In our current study, we analyzed the role of EAPP under DNA damage conditions and examined the impact of its overexpression and knockdown. The treatment with drugs that interfered with cell-cycle progression by activating cellular checkpoints revealed that the fraction of G1 cells was much higher in EAPPoverexpressing than normal U2OS cells (Figure 1). This indicates that more EAPP either slowed down the cell cycle or even arrested these cells in G1, or that EAPP somehow abolished the effects of the drugs. The only plausible mechanism for blocking the drugs seemed to be the activation of multidrug resistance $(M D R)$ genes, encoding large transmembrane transporters able to remove toxic substances from a cell (Gutmann et al., 2010). To examine this possibility we compared the levels of several MDR proteins in normal EAPP overexpressing cells. We indeed detected a stimulating effect on the expression of P-glycoprotein (Gros et al., 1986; Goda et al., 2009), but the measurement of the efflux of a dye revealed that the drug-transport activity of EAPP overexpressing cells was not increased and could thus not explain our observations (not shown). Transfection with either a GFP or a GFP-EAPP expression vector and the separate assessment of transfectionpositive and transfection-negative cells confirmed that EAPP overexpression results in G1 arrest. Earlier findings that EAPP stimulates cell-cycle progression (Novy et al., 2005) might be explained by a differing methodology. At that time we were not able to separately analyze transfected and untransfected cells.

The growth-inhibitory activity of EAPP turned out to be p21-dependent as it was abrogated by the knockdown of p21. In line with this finding, p21 protein and mRNA levels, as well as its promoter activity, went up with increasing, and down with lowered EAPP levels showing that EAPP influences the expression of p21. This, and the observation that U2OS cells approaching confluency increase both, their EAPP and p21, but not p53 levels suggested that EAPP is among the driving forces behind the increase of p21 in confluent cells (Figure 2). Furthermore, a knockdown of EAPP inhibits this cell density-dependent increase of p21 (Figure 8b).

The p21 promoter shows a complex pattern of regulation and a variety of DNA-binding factors, as 

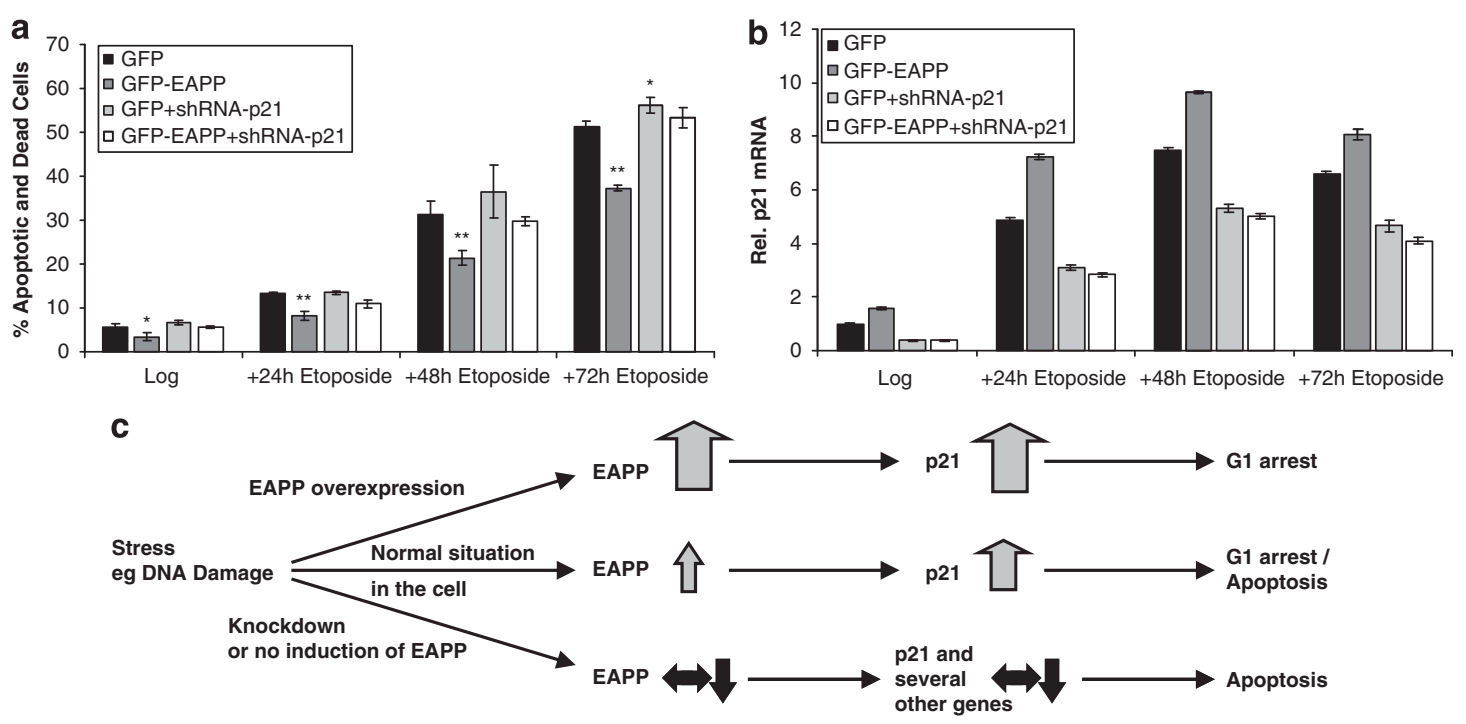

Figure 9 The antiapoptotic activity of EAPP depends on p21. (a) U2OS cells were transfected either with a GFP vector, a GFP-EAPP vector, a GFP plus a p21 knock down vector or a GFP-EAPP plus a p21 knockdown vector with a ratio of 3:1 (knock down versus GFP vector). Subsequently, the percentage of apoptotic cells was determined in the control group (Log) and after 24,48 , and $72 \mathrm{~h}$ treatment with etoposide. All data are presented as the mean \pm s.d. from at least three independent experiments. ${ }^{*} P<0.05$; $* * P<0.01$. (b) Relative amounts of p21 mRNA in these cells as determined by RT-PCR. Only about $25 \%$ of the cells were GFP positive, which reduced the overall effect. (c) A model showing the outcome of three different scenarios with elevated, normal and reduced levels of EAPP.

well as chromatin remodeling and histone-modifying complexes determine its activity (reviewed in (Gartel and Radhakrishnan, 2005; Abbas and Dutta, 2009)). The observed modulation of $\mathrm{p} 21$ promoter activity by EAPP could occur either by direct binding to DNA, by affecting other promoter-binding factors, or chromatinmodifying processes. ChIP assays demonstrated that EAPP associates with the region around the TATA box (Figure 4). The histone modification pattern in the vicinity of the TATA box was not affected by differing EAPP concentrations and thus does not seem to be involved (Supplementary Figure 3).

Whereas elevating or lowering EAPP had no impact on the binding of E2F1 and TBP, there was a clear reduction of promoter-bound TAF 1 , TAF 4 , Pol II and cdk9 (Figure 5b,c and d). EAPP might thus be required for the efficient assembly of the pre-initiation complex at the p21 promoter. Reduced binding of $\operatorname{cdk} 9$, which is required for elongation (Peng et al., 1998), might just be a consequence of inefficient initiation or it might itself require EAPP for promoter association. Binding of Sp1 on the other hand was elevated upon EAPP knock down (Figure 4e). This is in line with a very recent report (Chen et al., 2010) showing that EAPP can directly bind to DNA and compete with Sp1 for its binding site. Moreover, two of the six Sp1 binding sites seem to mediate the activity of EAPP on the p21 promoter as their mutation abolished any effect of an EAPP knockdown (Figures $3 \mathrm{e}$ and $\mathrm{g}$ ). This could mean that the putative role of EAPP in transcription initiation is more important for $\mathrm{p} 21$ promoter activity than binding of Sp1 to these sites.

p21 expression is strongly stimulated following DNA damage. This is primarily caused by damage-induced p53 but can also be seen to a lesser degree in p53 negative cells. The increase of EAPP under damage conditions suggested that it contributes to the p21 induction. This is also supported by the observation that the knockdown of EAPP severely hampers the p21 induction after DNA damage or HDAC inhibition (Figure 5; Supplementary Figure 4).

The observed increase of EAPP in many transformed cell lines (Novy et al., 2005) suggested that these cells benefit from higher EAPP levels despite the concomitant stimulation of growth-retarding p21. Inhibition of apoptosis seemed to be a likely mechanism. And indeed, overexpression of EAPP impeded DNA damage but also E2F1-induced apoptosis (Figure 6), whereas its knockdown resulted in apoptosis even without damage. As this apoptosis also occurred in p53-negative T98G cells, it is at least not absolutely dependent on p53 (Figure 7). The antiapoptotic activity of EAPP is also mediated mainly by p21 as it almost completely abolished by a concurrent knockdown of p21 (Figure 9). To find out whether a modest reduction of EAPP levels can also make a difference under stress conditions, we treated cells with low amounts of etoposide, which perhaps comes closer to naturally occurring events a cell can encounter. Then we compared cells with normal and moderately lowered EAPP content. This revealed that a modest reduction, which only slightly impairs cell proliferation under normal growth conditions, drastically lowered their viability following DNA damage (Figure 8).

Taken together our findings suggest that EAPP is indispensable for the survival of a cell. The required amount of EAPP seems to depend on the environmental conditions. Under optimal conditions for cell growth less is needed, whereas stress seems to favor cells expressing more EAPP (Figure 9c). This might also be an explanation for the high EAPP levels observed in many transformed cells. The CDK inhibitor p21 seems 
to have an important role as a mediator of the antiapoptotic activity of EAPP. In the absence of sufficient EAPP, the assembly of the transcription initiation complex at the p21 promoter seems to be perturbed. Depending on the extent of the reduction of EAPP, p21 is downregulated or just not upregulated, and under stress conditions cannot carry out its cell-protecting functions. Most likely other proteins beside p21 are also involved in apoptosis caused by the loss of EAPP, as in unperturbed growing cells a p21 knockout has no severe effect (Deng et al., 1995). Preliminary evidence suggests that the role of EAPP in transcription is not limited to the p21 promoter. Active promoters are occupied by multiple types of complexes (Sikorski and Buratowski, 2009) and EAPP seems to be an important component of at least some of them. Lowering EAPP levels influenced the expression of some of the genes examined (unpublished results). Among them are genes encoding important cell-cycle regulators like proliferating cell nuclear antigen, cyclin B, cdk1 and p27 the level of which went down with EAPP. To examine which genes are influenced by EAPP and to scrutinize the biochemical details of its activity will be focus of future experiments.

\section{Materials and methods}

\section{Plasmids, reporter constructs and reagents.}

pCIneo-HA-EAPP, pEGFP-C, pEGFP-EAPP, pGAL-Luc, pSuper-EAPP-\#2 (Novy et al., 2005), p21-Luc and mutations thereof (Sowa et al., 1997), pSuper-p21 (Karakas et al., 2007), pSuper-SCR (Rayter et al., 2008) and pCIneo-HA-DP1(Helin et al., 1993) have been described. For the pGFP-E2F1 the E2F1 complementary DNA (cDNA) was recloned from the pGex2TE2F1 (Rotheneder et al., 1999) into the pEGFP-C vector. The pSuper-EAPP-\#1 and \#3 were generated by cloning a double stranded oligonucleotide with the sequences $5^{\prime}$-AAGTTGCAA CAGCTCCGAC- $3^{\prime}$ for \#1 and 5'-GATTCCAACAAATGACG AA- $3^{\prime}$ for $\# 3$ of the EAPP cDNA as an inverted repeat into the pSuper vector. The impact of individual and combined transfection of pSuper-EAPP-\#1, \#2 and \#3 is shown in Supplementary Figure 1. Etoposide, nocodazole, methyl-methanesulfonate and colchicine were purchased from Sigma (Taufkirchen, Germany).

\section{Cell culture and transfection}

U2OS and T98G cells were cultured in DMEM containing $10 \%(\mathrm{vol} / \mathrm{vol})$ fetal calf serum. Cells were transfected for $16 \mathrm{~h}$ using PerFectin (Genlantis, San Diego, CA, USA). Following a change of the medium, the cells were grown for additional $24-48 \mathrm{~h}$. As control vector for mock transfections we used either pEGFP-C (Clontech, Mountain View, CA, USA) for the expression of GFP, pSuper-Scrambled for the expression of an unspecific small interfering RNA, or an empty pCI-neo vector (Clontech).

\section{Western blot analysis, antibodies, RNA isolation and $R T-P C R$}

Whole-cell extracts were prepared by lysing the cells using a lysis buffer $(20 \mathrm{~mm}$ Tris pH8, $100 \mathrm{~mm} \mathrm{NaCl}, 1 \mathrm{~mm}$ EDTA, $0.5 \% \mathrm{NP}-40$ ). The separation was performed by $8-14 \%$ sodium dodecyl sulfate-PAGE. Proteins were then transferred onto nitrocellulose membranes and probed with indicated antibodies, followed by enhanced chemiluminescence detection. RNA isolation was done with the TRIzol Reagent from Invitrogen (Carlsbad, CA, USA), following the recommended protocol. The cDNA was prepared with the Revert Aid First Strand cDNA Synthesis Kit from Fermentas (Burlington, Canada) and PCR was performed with a Maxima Hot Start Green PCS Master Mix from Fermentas.

\section{Luciferase reporter assay}

Luciferase reporter assays were carried out as previously described (Novy et al., 2005) with full-length or truncated p21 promoter-luciferase reporter constructs (Sowa et al., 1997). $\beta$-Galactosidase activity was assayed in parallel as a control for the transfection efficiency (Novy et al., 2005).

\section{Chromatin immunoprecipitation assays}

ChIP's were carried out as previously described (Hauser et al., 2002). Following Antibodies were used: Pol II (N-20), TAF1 (6B3), TAF4 (4A6), TBP (SI-1), CDK9 (H-169), SP1 (PEP-2) and E2F1 (KH95) from Santa Cruz Biotechnology (Santa Cruz, CA, USA), H3 (1791) from Abcam (Cambridge, UK), H3ac (06599), H4ac (06-866), S10Ph (05-598) and K9ac (06-942) from Upstate (Millipore, Billerica, MA, USA) and the EAPP antibody. Input was used in a 1/30 dilution and PCRs were performed with a Maxima Hot Start Green PCS Master Mix (Fermentas, St. Leon-Rot, Germany) and products were resolved on a $2 \%$ agarose gel. ImageQuant 5.2 (Molecular Dynamics, Krefeld, Germany) was used to quantify three independent experiments in comparison with the input.

\section{Cell-cycle analysis}

The cell-cycle distribution was measured with DAPI (Merck, Darmstadt, Germany, Figure 1a), PI (Sigma, Figures 2a, 7a, b and 8c), Hoechst 33258 (Invitrogen, Figures 1b, 2c, and 6a), or Draq5 (Biostatus Limited, Leicestershire, UK; Figure 6c). Cells were trypsinized, washed once with phosphate-buffered saline and around $5 \times 10^{5}$ cells were taken for analysis. For Hoechst 33258 and Draq5, which stain viable cells, appropriate concentrations of the dyes were used and incubated for $20 \mathrm{~min}$ on $4{ }^{\circ} \mathrm{C}$ in the dark (Draq5 $10 \mu \mathrm{m}$, Hoechst $332585 \mu \mathrm{g} /$ $\mathrm{ml})$. For DAPI and PI cells were fixed in $85 \%$ ethanol and incubated at least $30 \mathrm{~min}$ on ice. PI was used in a final concentration of $50 \mu \mathrm{g} / \mathrm{ml}$ and $100 \mu \mathrm{g} / \mathrm{ml}$ RNAse Typ 1-A was added and incubated for $30 \mathrm{~min}$ at room temperature in the dark. DAPI concentration was $2 \mathrm{ng} / \mathrm{ml}$ and fixed cells were incubated for $20 \mathrm{~min}$ in the dark at $4{ }^{\circ} \mathrm{C}$. To analyze the cellcycle distribution different devices were used. DAPI staining was measured with a Pas-III from Partec (Muenster, Germany), PI and Draq5 with a FACS-Calibur (BD Bioscience, San Jose, CA, USA), and Hoechst 33258 with a FACS-Aria (BD Bioscience). Hoechst 33258 and Draq5 allowed an additional staining with and gating for GFP. With the FACS-Calibur and FACS-Aria cell debris and doublets were excluded.

\section{Apoptosis and cell count}

Cells were counted with a CASY Cell Counter TTC (Schärfe System, Reutlingen, Germany). To detect apoptosis different assays were carried out. For all procedures cells were trypsinized, washed once with phosphate-buffered saline and around $5 \times 10^{5}$ cells were taken for measurement. The same procedure as described in the cell cycle analysis part was applied for sub-G1 analysis. Beforehand a threshold was set to discriminate against the cell debris. For the Vybrant Apoptosis Assay Kit (Invitrogen) cells were stained with PI and YO-PRO 
according to the protocol from Invitrogen. YO-PRO enters only into early apoptotic cells, whereas PI stains all permeabilized cells. Again a threshold was set to exclude cell debris. Necrotic cells have either a higher forward scatter signal due to cell swelling or disappear in the cell debris upon bursting. In contrast, apoptotic cells have a smaller forward scatter signal before they give origin to many small apoptotic bodies, which generally end up as debris. YO-PRO-positive cells with a smaller forward scatter were gated and separated into PI-positive cells (late apoptosis or already dead cells) and PI-negative cells (early apoptosis). Hoechst 33258 brightly stains the condensed chromatin of apoptotic cells, hence, the fluorescence intensity increases. A threshold excluding the cell debris was set and GFP-positive cells were gated and percentage of cells with higher Hoechst 33258 values and smaller forward scatter values were measured. All flowcytometry experiments were done with a FACS-Calibur or a FACS-Aria from BB Bioscience.

\section{Data analysis}

Data in all experiments are represented as mean \pm s.d. Statistical analysis was carried out using unpaired $t$-test. The $P$-values of $<0.05$ were considered to be statistically significant. $* P<0.05 ; * * P<0.01$

\section{References}

Abbas T, Dutta A. (2009). p21 in cancer: intricate networks and multiple activities. Nat Rev Cancer 9: 400-414.

Asada M, Yamada T, Ichijo H, Delia D, Miyazono K, Fukumuro K et al. (1999). Apoptosis inhibitory activity of cytoplasmic p21 (Cip1/WAF1) in monocytic differentiation. EMBO $J \mathbf{1 8}$ $1223-1234$

Baptiste-Okoh N, Barsotti AM, Prives C. (2008). Caspase 2 is both required for $\mathrm{p} 53$-mediated apoptosis and downregulated by $\mathrm{p} 53$ in a p21-dependent manner. Cell Cycle 7: 1133-1138.

Blagosklonny MV. (2002). Are p27 and p21 cytoplasmic oncoproteins? Cell Cycle 1: 391-393.

Cazzalini O, Scovassi AI, Savio M, Stivala LA, Prosperi E. (2010). Multiple roles of the cell cycle inhibitor p21(CDKN1A) in the DNA damage response. Mutat Res 704: 12-20.

Chen J, Jackson PK, Kirschner MW, Dutta A. (1995). Separate domains of p21 involved in the inhibition of Cdk kinase and PCNA. Nature 374: 386-388.

Chen J, Saha P, Kornbluth S, Dynlacht BD, Dutta A. (1996). Cyclinbinding motifs are essential for the function of p21CIP1. Mol Cell Biol 16: 4673-4682.

Chen K, Ou XM, Wu JB, Shih JC. (2010). Transcription factor EAPP, $\mathrm{R} 1$ and Sp1 cooperatively regulate glucocorticoid activation of monoamine oxidase B. Mol Pharmacol (e-pub ahead of print).

Delavaine L, La Thangue NB. (1999). Control of E2F activity by p21Waf1/Cip1. Oncogene 18: 5381-5392.

Deng C, Zhang P, Harper JW, Elledge SJ, Leder P. (1995). Mice lacking p21CIP1/WAF1 undergo normal development, but are defective in G1 checkpoint control. Cell 82: 675-684.

el-Deiry WS, Tokino T, Velculescu VE, Levy DB, Parsons R, Trent JM et al. (1993). WAF1, a potential mediator of p53 tumor suppression. Cell 75: 817-825.

Flores-Rozas H, Kelman Z, Dean FB, Pan ZQ, Harper JW, Elledge SJ et al. (1994). Cdk-interacting protein 1 directly binds with proliferating cell nuclear antigen and inhibits DNA replication catalyzed by the DNA polymerase delta holoenzyme. Proc Nat Acad Sci U S A 91: 8655-8659.

Gartel AL, Radhakrishnan SK. (2005). Lost in transcription: p2 repression, mechanisms, and consequences. Cancer Res $\mathbf{6 5}$ $3980-3985$.

\section{Conflict of interest}

The authors declare no conflict of interest.

\section{Disclaimer}

The following material is original research, has not been previously published and has not been submitted for publication elsewhere.

\section{Acknowledgements}

We are grateful to $\mathrm{H}$ Nomura, BH Park, A Ashworth, and $\mathrm{N}$ Heintz for expression vectors. We thank Christian Seiser for helpful discussions and the histone antibodies, Erhard Wintersberger and Christian Seiser for critically reading this manuscript, Ingrid Mudrak and Egon Ogris for help with the generation of the monoclonal EAPP antibody, and Thomas Sauer for assistance with the FACS analysis. This work was supported by the Austrian FWF (Grant P18417) and by the Herzfelder'sche Familienstiftung.

Gartel AL, Tyner AL. (2002). The role of the cyclin-dependent kinase inhibitor p21 in apoptosis. Mol Cancer Ther 1: 639-649.

Giono LE, Manfredi JJ. (2006). The p53 tumor suppressor participates in multiple cell cycle checkpoints. J Cell Physiol 209: 13-20.

Goda K, Bacso Z, Szabo G. (2009). Multidrug resistance through the spectacle of P-glycoprotein. Curr Cancer Drug Targets 9: 281-297.

Goubin F, Ducommun B. (1995). Identification of binding domains on the p21Cip1 cyclin-dependent kinase inhibitor. Oncogene 10: 2281-2287.

Gros P, Ben Neriah YB, Croop JM, Housman DE. (1986). Isolation and expression of a complementary DNA that confers multidrug resistance. Nature 323: 728-731.

Gutmann DA, Ward A, Urbatsch IL, Chang G, van Veen HW. (2010). Understanding polyspecificity of multidrug $\mathrm{ABC}$ transporters: closing in on the gaps in ABCB1. Trends Biochem Sci 35: 36-42.

Hartwell LH, Weinert TA. (1989). Checkpoints: controls that ensure the order of cell cycle events. Science 246: 629-634.

Hauser C, Schuettengruber B, Bartl S, Lagger G, Seiser C. (2002). Activation of the mouse histone deacetylase 1 gene by cooperative histone phosphorylation and acetylation. Mol Cell Biol 22: 7820-7830.

Helin K, Wu CL, Fattaey AR, Lees JA, Dynlacht BD, Ngwu C et al. (1993). Heterodimerization of the transcription factors E2F-1 and DP-1 leads to cooperative trans-activation. Genes Dev 7: 1850-1861.

Idziorek T, Estaquier J, De Bels F, Ameisen JC. (1995). YOPRO-1 permits cytofluorometric analysis of programmed cell death (apoptosis) without interfering with cell viability. $J$ Immunol Methods 185: 249-258.

Janicke RU, Sohn D, Essmann F, Schulze-Osthoff K. (2007). The multiple battles fought by anti-apoptotic p21. Cell Cycle 6: 407-413.

Karakas B, Weeraratna AT, Abukhdeir AM, Konishi H, Gustin JP, Vitolo MI et al. (2007). P21 gene knock down does not identify genetic effectors seen with gene knock out. Cancer Biol Ther 6: $1025-1030$.

Kawasaki T, Tomita Y, Bilim V, Takeda M, Takahashi K, Kumanishi T. (1996). Abrogation of apoptosis induced by DNA-damaging agents in human bladder-cancer cell lines with p21/WAF1/CIP1 and/or p53 gene alterations. Int J Cancer 68: 501-505. 
Kitaura H, Shinshi M, Uchikoshi Y, Ono T, Iguchi-Ariga SM, Ariga H. (2000). Reciprocal regulation via protein-protein interaction between c-Myc and p21(cip1/waf1/sdil) in DNA replication and transcription. J Biol Chem 275: 10477-10483.

Kornberg RD. (2007). The molecular basis of eukaryotic transcription. Proc Natl Acad Sci USA 104: 12955-12961.

Lagger G, Doetzlhofer A, Schuettengruber B, Haidweger E, Simboeck E, Tischler J et al. (2003). The tumor suppressor p53 and histone deacetylase 1 are antagonistic regulators of the cyclindependent kinase inhibitor p21/WAF1/CIP1 gene. Mol Cell Biol 23: 2669-2679.

Li AG, Piluso LG, Cai X, Gadd BJ, Ladurner AG, Liu X. (2007a). An acetylation switch in p53 mediates holo-TFIID recruitment. Mol Cell 28: 408-421.

Li B, Carey M, Workman JL. (2007b). The role of chromatin during transcription. Cell 128: 707-719.

Novy M, Pohn R, Andorfer P, Novy-Weiland T, Galos B, Schwarzmayr L et al. (2005). EAPP, a Novel E2F Binding Protein That Modulates E2F-dependent Transcription. Mol Biol Cell 16: 2181-2190.

Peng J, Zhu Y, Milton JT, Price DH. (1998). Identification of multiple cyclin subunits of human P-TEFb. Genes Dev 12: 755-762.

Perucca P, Cazzalini O, Madine M, Savio M, Laskey RA, Vannini V et al. (2009). Loss of p21 CDKN1A impairs entry to quiescence and activates a DNA damage response in normal fibroblasts induced to quiescence. Cell Cycle 8: 105-114.

Phillips AC, Vousden KH. (2001). E2F-1 induced apoptosis. Apoptosis 6: $173-182$.

Pietenpol JA, Stewart ZA. (2002). Cell cycle checkpoint signaling: cell cycle arrest versus apoptosis. Toxicology 181-182: 475-481.

Qin XQ, Livingston DM, Kaelin Jr WG., Adams PD. (1994). Deregulated transcription factor E2F-1 expression leads to S-phase entry and p53-mediated apoptosis. Proc Natl Acad Sci USA 91: 10918-10922.

Rayter S, Elliott R, Travers J, Rowlands MG, Richardson TB, Boxall $\mathrm{K}$ et al. (2008). A chemical inhibitor of PPM1D that selectively kills cells overexpressing PPM1D. Oncogene 27: 1036-1044.

Roninson IB. (2002). Oncogenic functions of tumour suppressor p21(Waf1/Cip1/Sdil): association with cell senescence and tumourpromoting activities of stromal fibroblasts. Cancer Lett 179: $1-14$.

Rotheneder H, Geymayer S, Haidweger E. (1999). Transcription factors of the Sp1 family: interaction with $\mathrm{E} 2 \mathrm{~F}$ and regulation of the murine thymidine kinase promoter. J Mol Biol 293: 1005-1015.

Rozan LM, El-Deiry WS. (2007). p53 downstream target genes and tumor suppression: a classical view in evolution. Cell Death Differ 14: $3-9$.

Schwarzmayr L, Andorfer P, Novy M, Rotheneder H. (2008). Regulation of the E2F-associated phosphoprotein promoter by GC-box binding proteins. Int J Biochem Cell Biol 40: 2845-2853.

Shan B, Lee WH. (1994). Deregulated expression of E2F-1 induces S-phase entry and leads to apoptosis. Mol Cell Biol 14: 8166-8173.

Sherr CJ, Roberts JM. (2004). Living with or without cyclins and cyclin-dependent kinases. Genes Dev 18: 2699-2711.

Sikorski TW, Buratowski S. (2009). The basal initiation machinery: beyond the general transcription factors. Curr Opin Cell Biol 21: 344-351.

Sowa Y, Orita T, Minamikawa S, Nakano K, Mizuno T, Nomura H et al. (1997). Histone deacetylase inhibitor activates the WAF1/Cipl gene promoter through the $\mathrm{Sp} 1$ sites. Biochem Biophys Res Commun 241: $142-150$.

Suzuki A, Tsutomi Y, Miura M, Akahane K. (1999). Caspase 3 inactivation to suppress Fas-mediated apoptosis: identification of binding domain with $\mathrm{p} 21$ and ILP and inactivation machinery by p21. Oncogene 18: 1239-1244.

Waga S, Hannon GJ, Beach D, Stillman B. (1994). The p21 inhibitor of cyclin-dependent kinases controls DNA replication by interaction with PCNA. Nature 369: 574-578.

Waldman T, Lengauer C, Kinzler KW, Vogelstein B. (1996). Uncoupling of $\mathrm{S}$ phase and mitosis induced by anticancer agents in cells lacking p21. Nature 381: 713-716.

Wu X, Levine AJ. (1994). p53 and E2f-1 cooperate to mediate apoptosis. Proc Natl Acad Sci US A 91: 3602-3606.

Zhu H, Chang BD, Uchiumi T, Roninson IB. (2002). Identification of promoter elements responsible for transcriptional inhibition of polo-like kinase 1 and topoisomerase IIalpha genes by p21 (WAF1/CIP1/SDI1). Cell Cycle 1: 59-66.

\section{(c)}

SOMERIGHTSRE

This work is licensed under the Creative Commons Attribution-NonCommercial-No Derivative

Works 3.0 Unported License. To view a copy of this license, visit http://creativecommons.org/licenses/by-nc-nd/3.0/

Supplementary Information accompanies the paper on the Oncogene website (http://www.nature.com/onc) 